\title{
O FINANCIAMENTO DA SAÚDE FRENTE AO NOVO REGIME FISCAL
}

Funding for health in the new Brazilian tax regime

${ }^{1}$ Faculdade de Direito. Universidade de São Paulo. São Paulo/SP, Brasil. Correspondência: ana.romao@usp.br

Recebido: 18/12/2017. Revisão: 16/04/2018. Aprovado: 23/04/2018. 


\section{RESUMO}

O objetivo deste artigo é analisar o financiamento da saúde pública no Brasil, em especial as consequências da adoção do novo regime fiscal. Para isso, o método utilizado foi o levantamento bibliográfico nas principais bases de dados disponíveis, complementado por textos jornalísticos e análise das Ações Diretas de Inconstitucionalidade n. 5.595 e n. 5.658, que discutiram o tema. O artigo é dividido em quatro partes: (i) introdução sobre a constitucionalização do direito à saúde; (ii) exposição sobre os modos de financiamento da saúde pública, com enfoque nas Emendas Constitucionais n. 29/2000, n. 86/2015 e n. 95/2016; (iii) exame dos impactos do novo regime fiscal no setor da saúde, com destaque para suas implicações na judicialização da saúde; e (iv) a conclusão de que o novo regime fiscal trouxe medidas de austeridade que, além de reduzirem os recursos disponíveis para a saúde, impedem a expansão dos serviços de atendimento à população e têm grande potencial de aumentar as demandas judiciais por tratamentos e medicamentos.

\section{Palavras-Chave}

Financiamento da Saúde; Novo Regime Fiscal; Orçamento Público; Saúde Pública.

\section{ABSTRACT}

The objective of this article is to analyze public health funding in Brazil, especially the consequences of the newly adopted fiscal regime. The method used was bibliographical survey, gathering articles from the main available databases, newspaper articles and the analysis of the Direct Actions of Unconstitutionality no. 5595 and no. 5658, which discussed the matter. The article is divided into four parts: (i) an introduction on the constitutionalization of the right to health; (ii) an exposition on public health funding approaches focusing on the Constitutional Amendments number 29/2000, 86/2015 and 95/2016; (iii) the examination of the impacts of the new fiscal regime on the health sector and a highlight of the impact of these measures in cases of health judicialization; and (iv) with the conclusion that the new fiscal regime has introduced austerity measures, which, in addition to reducing the health resources available, discourage the expansion of public health care, leading to a great potential of increasing legal demands for treatments and medicines.

\section{Keywords}

Public Health Finance; New Tax System; Public Budget; Public Health. 


\section{Introdução}

O Brasil é, entre os países que possuem um sistema universal de saúde, o que menos investe no setor de saúde pública. Em 2013, o país teve um gasto público de US\$ 591 per capita com saúde, valor bastante inferior a sistemas semelhantes, como o da França (US\$ 3.360) e o do Reino Unido (US\$2.766), e até a países sem um sistema único, como a Argentina (US\$ 1.167)1. Tais dados demonstram a o subfinanciamento histórico da saúde no Brasil, que tende a piorar com a adoção de medidas de contenção de gastos estatais, materializadas nas recentes Emendas Constitucionais (EC) n. 86/2015 e n. 95/2016 .

O objetivo deste trabalho é analisar o modo de financiamento da saúde no Brasil, destacando as principais mudanças advindas do novo regime fiscal e seu impacto negativo para a concretização do direito à saúde.

O Brasil deu um grande passo em 1988, com a consagração do acesso à saúde como direito fundamental e com a criação do Sistema Único de Saúde (SUS). No entanto, a concretização desse direito tem sofrido severos golpes de medidas de contingenciamento de gastos, tomadas pelo Congresso Nacional a fim de superar a atual crise econômica. O novo regime fiscal instituído pela EC n. 95/2016 congela gastos primários por um período de 20 anos, afetando diretamente o financiamento das áreas de saúde e educação.

Ao restringir os recursos da saúde, o Brasil cria uma espiral de efeitos negativos para a população, em especial as camadas mais baixas, dependentes do sistema público de saúde. Em um momento de crise socioeconômica, as demandas por serviços públicos crescem, enquanto o novo regime fiscal vai na contramão desse movimento, debilitando o atendimento em saúde quando ele é mais necessário. Entre as consequências disso, destaca-se o problema da judicialização, que hoje representa parte significativa do orçamento da saúde e que, com as falhas no atendimento, tende a aumentar. A título exemplificativo, o Ministério da Saúde gastou em $2015 \mathrm{R} \$ 1$ bilhão para tender às demandas judiciais, sendo que seu orçamento total naquele ano foi de $\mathrm{R} \$ 121$ bilhões $^{4}$.

\footnotetext{
${ }^{1}$ VIEIRA, Fabiola Sulpino; BENEVIDES, Rodrigo Pucci de Sá e. Os impactos do novo regime fiscal para o financiamento do Sistema Único de Saúde e para a efetivação do direito à saúde no Brasil. Brasília-DF: Ipea, 2016. p. 17. (Nota técnica $\left.n^{\circ} 28\right)$.

${ }^{2}$ BRASIL. Emenda Constitucional n. 86, de 17 de março de 2015. Altera os arts. 165, 166 e 198 da Constituição Federal, para tornar obrigatória a execução da programação orçamentária que especifica. Disponível em: http://www.planalto.gov.br/ccivil_03/Constituicao/Emendas/Emc/emc86.htm. Acesso em: 22 jan. 2019.

${ }^{3}$ BRASIL. Câmara dos Deputados. Emenda Constitucional n. 95, de 2016. Altera o Ato das Disposições Constitucionais Transitórias, para instituir o Novo Regime Fiscal, e dá outras providências. Disponível em: https://www2.camara.leg.br/legin/fed/emecon/2016/emendaconstitucional-95-15-dezembro-2016784029-publicacaooriginal-151558-pl.html. Acesso em: 22 jan. 2019.

${ }^{4}$ TRIBUNAL DE CONTAS DA UNIÃO - TCU. Relatório de Auditoria TC 009.253/2015-7. Relator: Bruno Dantas. Sessão: 16/08/2017. Disponível em: http://portal.tcu.gov.br/imprensa/noticias/aumentam-os-gastospublicos-com-judicializacao-da-saude.htm. Acesso em: 15 abr. 2018.
} 


\section{Método}

Este trabalho adotou levantamento bibliográfico das principais bases de artigos disponíveis (Scielo, Capes, PUBMED), complementado com textos jornalísticos e análise das Ações Diretas de Inconstitucionalidade (ADI) n. $5595^{5}$ e n. $5658^{6}$, que discutiram o tema. $\mathrm{O}$ artigo é dividido em quatro partes: (i) breve introdução sobre a constitucionalização do direito à saúde; (ii) exposição sobre os modos de financiamento da saúde pública, com enfoque nas Emendas Constitucionais n. 29/20007 n. 86/2015 e n. 95/2016; (iii) exame dos impactos do novo regime fiscal no setor da saúde (tomando a liberdade de incluir tanto a EC n. 86/2015 quanto a EC n. 95/2016), com destaque para suas implicações na judicialização da saúde; e (iv) conclusão.

\section{0 direito à saúde como direito fundamental}

A saúde, embora um dos atributos mais essenciais ao ser humano, foi durante muito tempo negligenciada dentro do funcionamento estatal brasileiro. Até a segunda metade do século XX, esse setor era majoritariamente controlado por agentes privados, sendo abordado apenas tangencialmente pela legislação. Os serviços de saúde eram predominantemente prestados por entidades filantrópicas, com destaque para as Santas Casas de Misericórdia, ainda hoje presentes na maioria dos municípios brasileiros. Como resultado, grande parte da população ficava desassistida diante dos escassos recursos destinados para o Ministério da Saúde promover políticas públicas que permitissem o acesso a cuidados básicos de saúde ${ }^{8}$.

Nos anos 1960, o sistema de saúde do país encontrava-se dividido entre o sistema de medicina previdenciária e o de saúde pública. O primeiro, ligado a institutos privados de pensão, cobria os trabalhadores formais de zonas urbanas, enquanto o segundo, vinculado ao Ministério da Saúde, ocupava-se de trabalhadores de zonas rurais e setores de baixa renda, focando a prática preventiva. Para esses trabalhadores, $o$ atendimento individual de caráter "curativo" era responsabilidade do Ministério da Previdência e Assistência Social, que atuava por meio do Instituto Nacional de Assistência Médica da Previdência Social (Inamps) 9

\footnotetext{
${ }^{5}$ SUPREMO TRIBUNAL FEDERAL - STF. ADI n. 5595. Ministro Ricardo Lewandowski. Disponível em: http:// www.stf.jus.br/portal/processo/verProcessoAndamento.asp?numero=5595\&classe=ADI\&origem=AP\&rec urso=0\&tipoJulgamento=M. Acesso em: 20 jan. 2017

${ }^{6}$ SUPREMO TRIBUNAL FEDERAL - STF. ADI n. 5658. Ministra Rosa Weber. Disponível em: http://portal.stf.jus. br/processos/detalhe.asp?incidente $=5132872$. Acesso em: 22 jan. 2019.

${ }^{7}$ BRASIL. Emenda Constitucional n. 29, de 13 de setembro de 2000. Altera os arts. 34, 35, 156, 160 , 167 e 198 da Constituição Federal e acrescenta artigo ao Ato das Disposições Constitucionais Transitórias, para assegurar os recursos mínimos para o financiamento das ações e serviços públicos de saúde. Disponível em: http://www.planalto.gov.br/ccivil_03/constituicao/Emendas/Emc/emc29.htm. Acesso em: 22 jan. 2019.

8PAIVA, Carlos Henrique Assunção; TEIXEIRA, Luiz Antônio. Reforma sanitária e a criação do Sistema Único de Saúde: Notas sobre contextos e autores. Hist. cienc. saude-Manguinhos [online]. Rio de Janeiro, v. 21, n. 1, p. 15-35, jan./mar. 2014. http://dx.doi.org/10.1590/S0104-59702014000100002. Disponível em: http:// www.scielo.br/pdf/hcsm/v21n1/0104-5970-hcsm-21-1-00015.pdf.

9SARLET, Ingo Wolfgang; FIGUEIREDO, Mariana Filchtiner. Algumas considerações sobre o direito fundamental à proteção e promoção da saúde aos 20 anos da Constituição Federal de 1988. Revista de Direito do Consumidor, São Paulo, v. 17, n.67, p. 125-172, jul./set. 2008.
} 
Naquele período, o Ministério da Saúde recebia menos de 20\% dos recursos federais destinados à saúde, cuja maior parte ia para a Seguridade Social (que vinculava o sistema Inamps). O financiamento era majoritariamente da esfera federal, que provia $70 \%$ dos recursos ${ }^{10}$.

Com o Segundo Plano Nacional do Desenvolvimento (PND), em meados da década de 1970 - portanto, ainda durante o regime militar -, a saúde ganhou destaque entre os investimentos estatais. Foi criado o Sistema Nacional de Saúde pela Lei n. 6.229/1975, ulteriormente substituído pelo Sistema Unificado e Descentralizado de Saúde (SUDS), em 1987. Ainda na década de 1970, o movimento sanitarista ganhou força em âmbito nacional, impulsionado pelo Centro Brasileiro de Estudos em Saúde (Cebes) e pela Associação Brasileira de Pós-Graduação em Saúde Coletiva (Abrasco). Bem-organizados e influentes, os sanitaristas elaboraram um novo projeto para a saúde pública no país, adotando na VIII Conferência Nacional de Saúde, em 1986, as bandeiras da universalização e da constitucionalização da saúde ${ }^{11}$.

A pressão popular, em especial desses movimentos, culminou na consagração do direito à saúde como direito fundamental na Constituição de $1988(\mathrm{CF} / 1988)^{12}$. Não só o artigo 196 garantiu a saúde como um direito de todos e dever do Estado, como o artigo 198 estabeleceu um modo programático de concretização desse direito, com a formação de uma rede regionalizada e hierarquizada baseada na descentralidade, na universalidade, na integralidade e na participação comunitária. Em 1990, a Lei n. 8.080/1990 ${ }^{13}$ concretizou essa previsão constitucional ao criar o SUS. O Estado, então, passou a ser o principal responsável pelo atendimento de saúde da população, recaindo sobre seus ombros o financiamento e a garantia do atendimento integral a todos.

\section{O financiamento da saúde}

\subsection{Previsão constitucional}

A CF/1988 incluiu a saúde como integrante do sistema de seguridade social, composto também pela assistência social e a previdência. $\mathrm{O}$ artigo 55 do Ato das Disposições Constitucionais Transitórias $(\mathrm{ADCT})^{14}$ estabeleceu a vinculação à

\footnotetext{
${ }^{10}$ CONSELHO NACIONAL DE SECRETÁRIOS DE SAÚDE - CONASS. O financiamento da saúde. Brasília-DF: Conass, 2011 (Coleção Progestores - para entender a gestão do SUS, n. 2).

${ }^{11}$ PAIVA, Carlos Henrique Assunção; TEIXEIRA, Luiz Antônio. op. cit., p.15-35.

${ }^{12}$ BRASIL. Constituição da República Federativa do Brasil de 1988. Disponível em: http://www.planalto.gov. br/ccivil_03/constituicao/constituicaocompilado.htm. Acesso em: 22 jan. 2019.

${ }^{13}$ BRASIL. Lei Federal n. 8.080, de 19 de setembro de 2009. Dispõe sobre as condições para a promoção, proteção e recuperação da saúde, a organização e o funcionamento dos serviços correspondentes e dá outras providências. Disponível em: http://www.planalto.gov.br/ccivil_03/leis/L8080.htm. Acesso em: 22 jan. 2019.

14 “Art. 55. Até que seja aprovada a lei de diretrizes orçamentárias, trinta por cento, no mínimo, do orçamento da seguridade social, excluído o seguro-desemprego, serão destinados ao setor de saúde." BRASIL. Senado Federal. Art. 55 (ADCT). Disponível em: https://www.senado.leg.br/atividade/const/con1988/ ADC1988_15.12.2016/art_55_.asp. Acesso em: 22 jan. 2019.
} 
saúde de 30\% dos recursos do orçamento da seguridade social (OSS), excluindo-se o seguro-desemprego.

Contudo, em 1994, visando a ajuste fiscal, o governo instituiu o Fundo Social de Emergência, hoje conhecido como Desvinculação de Receitas da União (DRU), que desvinculou parte das receitas afetadas à seguridade - receitas do Fundo de Participação dos Estados (FPE) e do Fundo de Participação dos Municípios (FPM) - para que pudesse ser utilizada em outros setores com maior necessidade de recursos segundo a discricionariedade da Administração Pública. Inicialmente medida temporária, a DRU foi prorrogada diversas vezes, perpetuando-se até os dias atuais.

A fim de driblar o déficit causado pela DRU, foi instituído em 1996 um novo imposto cuja renda se destinaria ao financiamento da saúde: a Contribuição Provisória sobre Movimentação Financeira (CPMF), cujo produto da arrecadação deveria ser destinado ao Fundo Nacional de Saúde (FNS) para financiamento de ações e serviços de saúde (Lei n. 9.311/1996, art. 18) ${ }^{15}$. Entretanto, o novo tributo não cumpriu seu papel redentor de aumentar os recursos para as ações e os serviços públicos de saúde, pois, na medida em que eram adicionadas suas arrecadações, outras contribuições sociais tiveram sua participação reduzida no financiamento da saúde. Na prática, o que ocorreu foi a substituição das fontes de receita, sem ganhos quantitativos, levando à extinção da CPMF em $2007^{16}$.

\subsection{A EC n. 29/2000}

A EC n. 29/2000 surgiu para delimitar o modus operandi do sistema de financiamento do SUS, uma vez que a previsão constitucional era de um sistema descentralizado. Assim, estabeleceram-se percentuais mínimos de aplicação dos recursos da União, Estados e Municípios em Ações e Serviços Públicos em Saúde.

Para a União, o valor mínimo de 2001 seria o montante aplicado em 2000 corrigido em 5\%; e nos anos subsequentes, até 2004, o mínimo seria o valor empenhado no ano imediatamente anterior, corrigido pela variação nominal do Produto Interno Bruto (PIB).

Os estados deveriam destinar à saúde ao menos $12 \%$ da arrecadação do Imposto sobre a Circulação de Mercadorias e Serviços (ICMS), do Imposto de Transmissão Causa Mortis (ITCM), do Imposto sobre a Propriedade de Veículos Automotores (IPVA) e das transferências constitucionais feitas pela União, deduzidas as parcelas destinadas aos respectivos municípios.

\footnotetext{
${ }^{15}$ BRASIL. Lei n. 9311, de 24 de outubro de 1996. Institui a Contribuição Provisória sobre Movimentação ou Transmissão de Valores e de Créditos e Direitos de Natureza Financeira - CPMF, e dá outras providências. Disponível em: http://www.planalto.gov.br/ccivil_03/LEIS/L9311.htm. Acesso em: 22 jan. 2019.

${ }^{16}$ MINISTÉRIO DA SAÚDE. ORGANIZAÇÃO PAN-AMERICANA DA SAÚDE. Financiamento público de saúde. Brasília-DF: Ministério da Saúde, 2013. (Série ECos - Economia da Saúde para a Gestão do SUS; Eixo 1, v. 1).
} 
Por fim, os municípios deveriam aplicar pelo menos 15\% da arrecadação do Imposto Predial e Territorial Urbano (IPTU), do Imposto de Transmissão Intervivos (ITBI), do Imposto sobre Serviços (ISS) e das transferências constitucionais feitas pela União e pelos estados aos municípios. Para o Distrito Federal, o percentual ficou em $12 \%$ ou $15 \%$ do valor arrecadado, dependendo da competência do imposto (estadual ou municipal).

A EC n. 29/2000 previa posterior regulamentação por lei complementar, em especial para definição de quais seriam as ações e políticas de saúde pública. A falta dessa lei abriu a possibilidade de muitos entes se escusarem do cumprimento das disposições ali presentes ${ }^{17}$. Foi apenas em 2012, com a Lei Complementar n. 141, que as previsões da EC n. 29/2000 foram esclarecidas.

Ainda assim, a EC n. 29/2000 trouxe resultados positivos ao conferir mais recursos para a saúde, incluindo maior participação de estados e municípios. Quando foi aprovada, em 2000, a União era responsável por cerca de $60 \%$ do aporte de recursos para o setor; após a emenda, verificou-se significativa queda nessa proporção. Em 2011, a participação da União chegou a 44\%, enquanto a dos estados subiu de $18,5 \%$ para $25,4 \%$ e a dos municípios, de $21,7 \%$ para $29,6 \%{ }^{18}$. Entre 2000 e 2011 , os estados e municípios mais que triplicaram o volume de recursos destinados à saúde, passando de $\mathrm{R} \$ 28$ bilhões para $\mathrm{R} \$ 89$ bilhões.

\subsection{A EC n. $86 / 2015$}

O sistema de financiamento da saúde imposto pela EC n. 29/2000 vigorou até 2015 , quando foi aprovada a EC n. 86/2015. Em meio a um contexto de crise econômica, visando ao reajuste das contas públicas e à implementação de medidas de austeridade, a EC n. 86/2015 instituiu o que se denominou "orçamento impositivo" e reviu os percentuais de vinculação à saúde ${ }^{19}$.

Alterando o artigo 165 da CF/1988, o legislador destinou verba equivalente a 1,2\% da receita corrente líquida (RCL) para as emendas individuais ao projeto de lei orçamentária encaminhado pelo Poder Executivo. Desse montante, metade deve se destinar a ações e serviços públicos de saúde. Dessa forma, estabeleceu-se um

\footnotetext{
${ }^{17}$ PIOLA, Sérgio F.; PAIVA, Andrea Barreto de; SÁ, Edvaldo Batista de; SERVO, Luciana Mendes Santos. Financiamento público da saúde: uma história à procura de rumo. Brasília-DF: Ipea, 2013. (Texto para Discussão $n^{\circ}$ 1846). Disponível em: http://repositorio.ipea.gov.br/bitstream/11058/1580/1/ TD_1846.pdf.

${ }^{18}$ Dados da Subsecretaria de Planejamento e Orçamento (SPO), do Ministério da Saúde, na esfera federal, e do Sistema de Informações sobre Orçamentos Públicos em Saúde (SIOPS), nas esferas estadual e municipal, extraídos em 27 de novembro de 2012.

${ }^{19}$ SCAFF, Fernando Facury. Surge o orçamento impositivo à brasileira pela Emenda Constitucional 86. Conjur, 24 mar. 2015, https://www.conjur.com.br/2015-mar-24/contas-vista-surge-orcamento-impositivobrasileira-ec-86. Acesso em: 12 abr. 2018.
} 
"financiamento de emendas parlamentares", obrigando a União a executar gastos que primordialmente atendiam às bases eleitorais dos parlamentares que as propuseram ${ }^{20}$.

Além disso, estabeleceu-se que a União passaria a aplicar um montante mínimo de $15 \%$ da RCL do respectivo exercício financeiro, enquanto que, no regime anterior, da LC n. 141/2012, a União aplicaria o montante empenhado no exercício anterior acrescido de, no mínimo, o percentual equivalente à variação nominal do PIB. A EC n. 86/2015 estabeleceu, ainda, os percentuais de 12\% da RCL dos estados e $15 \%$ da RCL dos municípios.

No sistema da EC n. 86/2015, não há possibilidade de variação da aplicação em razão das alterações econômicas, tornando-o menos flexível. Assim, eventual crescimento econômico posterior à recuperação econômica do país não implicaria crescimento dos recursos para a saúde, o que seria natural no sistema anterior. Por exemplo, no ano de 2013, o governo federal gastou quase $\mathrm{R} \$ 83$ bilhões em saúde, valor aumentado para $\mathrm{R} \$ 92$ bilhões em 2014 e R \$ 100,79 bilhões em 2015. Tais montantes representaram um crescimento respectivo de $10,6 \%$ e 9,6\%, acompanhando o crescimento econômico. Com o regime da EC n. 86/2015, não haveria reajustes conforme o PIB, de forma que o valor atingido seria muito menor, gerando um desequilíbrio ainda maior entre a capacidade econômica do país e seu investimento em serviços públicos.

Seu artigo $2^{\circ}$ também estabeleceu que o percentual de $15 \%$ seria atingido de maneira gradual, sendo gastos $13,2 \%$ em 2016; 13,7\% em 2017; 14,1\% em 2018; $14,5 \%$ em 2019 e, apenas em 2020, seria aplicado de forma plena o percentual de $15 \%$ da receita corrente líquida em ações e serviços de saúde. Tal aumento progressivo foi revogado com a edição da EC n. 95/2016.

Por último, a EC n. 86/2015 estabeleceu que os recursos da União obtidos pela participação do resultado ou compensação financeira pela exploração de petróleo e gás natural fariam parte desse percentual. Dessa forma, a verba de exploração deixaria de ser considerada adicional, passando a compor o montante vinculado e reduzindo ainda mais o investimento no setor.

\subsection{0 novo regime fiscal}

Visando ao reequilíbrio das finanças públicas e à retomada do crescimento econômico, foi promulgada em 15 de dezembro de 2016 pelo Congresso Nacional a polêmica Emenda Constitucional n. 95, que instituiu o novo regime fiscal.

Tal regime consiste na imposição de um teto para gastos primários pelos 20 anos seguintes. Dessa forma, cada Poder terá um limite de despesas primárias,

\footnotetext{
${ }^{20}$ SCAFF, Fernando Facury. op. cit.
} 
baseado nas despesas pagas em 2016, a serem reajustadas apenas pelo Índice Nacional de Preços ao Consumidor Amplo (IPCA) até o exercício de 2036.

Despesas primárias são justamente os gastos do governo referentes às políticas públicas, ou seja, gastos para manter os serviços públicos oferecidos à população, como saúde e educação. O gasto com pagamento de juros e amortização da dívida pública, portanto, não foi incluído no limite.

Salvado ${ }^{21}$ aponta que, com a financeirização da riqueza, os mercados passam a disputar cada vez mais recursos dos fundos públicos, destinando-os especialmente aos títulos públicos emitidos pelas autoridades monetárias e negociados no mercado financeiro, os quais constituem importante fonte de rendimentos para os investidores institucionais. Com as crises políticas e econômicas enfrentadas nos últimos anos, a nota de crédito do Brasil foi rebaixada por diversas agências de classificação de risco, aproximando-o do nível especulativo e, com isso, prejudicando a obtenção de investidores internacionais ${ }^{22}$. Para recuperar a política econômica e fazê-la voltar a ter credibilidade e reputação, atendendo às expectativas dos agentes, era necessário que a política fiscal fosse confiável e que o Estado conseguisse se manter como bom pagador. A fim de conseguir tal efeito, estabeleceram-se metas de contenção fiscal ou de geração de superávits fiscais ${ }^{23}$.

A partir desse contexto, é possível perceber a quem a EC n. 95/2016 serve: ao mesmo tempo em que sacrifica as verbas destinadas aos serviços voltados a camadas mais vulneráveis, garante recursos para o pagamento dos juros da dívida, favorecendo credores do Estado em detrimento de direitos sociais.

O novo regime fiscal é uma medida radical de contenção do empenho e da movimentação financeira das despesas primárias, desvinculando-as do desempenho econômico do país. Trata-se de um contingenciamento preventivo sem precedentes no mundo, mas que reflete uma prática relativamente comum no Brasil. De 2002 a 2008, o governo utilizou contingenciamento de despesas para atingir índices altos de superávit (maiores que 3\%), acima inclusive das metas orçamentárias previstas na Lei de Diretrizes Orçamentárias ${ }^{24}$. Com a crise econômica que afetou o país principalmente a partir de 2014, tal estratégia modificou-se de modo a constranger o

\footnotetext{
${ }^{21}$ SALVADOR, Evilasio. A privatização da previdência do servidor público: a Funpresp e a financeirização das aposentadorias e pensões. Cadernos Aslegis, v. 43, p. 107-128, 2011. Disponivel em: http://aslegis.org. br/files/cadernos/2011/Caderno43/CAD.43p107_A.privatizacao.da.previdencia.do.servidor.publico.a.fuv npresp.e.a.financeirizacao.das.aposentadorias.e.pensoes.pdf.

${ }^{22}$ BRITO, Adriano; COSTAS, Ruth. Brasil rebaixado: com perda de grau de investimento, dólar e juros podem ficar mais caros. BBC, 09 set. 2015. Disponivel em: http://www.bbc.com/portuguese/ noticias/2015/09/150909_brasil_rebaixamento_ab.

${ }^{23}$ OLIVEIRA, Fabrício. Economia e política das finanças públicas no Brasil. São Paulo: Hucitec, 2012. p. 253.

${ }^{24}$ PINTO, Élida Graziane. Novo regime fiscal e a constitucionalização do contingenciamento das despesas primárias obrigatórias. Physis, Rio de Janeiro, v. 26, n. 4, p. 1097-1101, out. 2016. http://dx.doi. org/10.1590/s0103-73312016000400002. Disponível em: http://www.scielo.br/scielo.php?script=sci_ arttext\&pid=S0103-73312016000401097\&lng=en\&nrm=iso.
} 
comportamento progressivo das despesas primárias obrigatórias, com as metas orçamentárias passando a exigir a contenção dos gastos. Nesse sentido, a EC n. 95/2016 é um aprofundamento dessa mentalidade contingencialista já existente, trazendo consequências ainda mais severas.

Com essa medida, a tendência é a distância cada vez maior entre os gastos e a receita arrecadada, pois, à medida que a economia voltar a crescer, a arrecadação aumentará, mas os gastos aplicados nos setores mais essenciais à população continuarão os mesmos. Os recursos sobressalentes, então, serão destinados às despesas que não foram congeladas - no caso, o pagamento da dívida pública.

\section{Os impactos na área da saúde resultantes da EC n. 86/2015 e da EC n. $95 / 2016$}

\subsection{As ADI n. 5.595 e n. $\mathbf{5 . 6 5 8}$}

O Ministério Público Federal, ao propor a Ação Direta de Inconstitucionalidade (ADI) n. 5.595, questionou a constitucionalidade da EC n. 86/2015 por reduzir o piso de gasto público federal com saúde, estabelecendo um regime progressivo até 2020. Segundo os cálculos demonstrados na petição, adotando-se esse regime, a perda de recursos no ano de 2016 seria de $\mathrm{R} \$ 10$ bilhões ${ }^{25}$, o que representaria uma queda de $0,54 \%$ em relação a 2015, considerando o reajuste de inflação calculado pelo IPCA. A argumentação desenvolvida ressalta que tal imposição geraria um retrocesso na concretização dos direitos fundamentais, o que é expressamente proibido na $\mathrm{CF} / 1988$. A falta de financiamento prejudicaria tanto o atendimento quanto o acesso aos serviços de saúde, desoperacionalizando o sistema idealizado nos artigos 196 e 198 da CF/1988.

Em agosto de 2017, o ministro Ricardo Lewandowski, do Supremo Tribunal Federal (STF), concedeu liminar dando provimento ao pedido de declaração de inconstitucionalidade.

Já a EC n. 95/2016 teve sua constitucionalidade questionada pela ADI n. 5.658, até o momento em análise no STF pela ministra Rosa Weber. Entre os argumentos apresentados, destaca-se o argumento jurídico de que a medida ofenderia o princípio democrático ao limitar a possibilidade de equilíbrio orçamentário: mantida a redação da emenda, cada presidente poderá propor projeto de lei complementar para alterar a correção dos limites do teto apenas uma única vez

\footnotetext{
${ }^{25}$ FUNCIA, Francisco. Nota de esclarecimento a respeito do cálculo das perdas decorrentes do início da vigência da nova regra da Emenda Constitucional n 86/2015 para calcular a aplicação mínima da União em ações e serviços públicos de saúde. Domingueira, Campinas, n. 4, 12 abr. 2015. Disponível em: http:// www.idisa.org.br/img/File/Domingueira\%20da\%20Sa\%C3\%BAde\%20-\%20004\%202015\%20-\%2012\%20 04\%202015.pdf. Acesso em: maio 2015.
} 
em seu mandato; impedindo-se ajustes nas despesas, haverá, com o passar dos exercícios fiscais, um descompasso entre despesas e receitas, gerando desequilíbrio fiscal. Além disso, a discricionariedade administrativa estaria limitada, uma vez que, com os recursos congelados, restam poucas possibilidades ao gestor. Os mandatários eleitos pela população não poderiam implantar seus planos de governo e a gestão dos recursos deixaria de ser democrática, uma vez que não poderiam alterar o orçamento de acordo com os interesses que os elegeram e que, em teoria, representam a vontade da maioria.

\subsection{Impactos sociais e econômicos do novo regime fiscal}

No Brasil, a crise econômica de 2008 trouxe efeitos tardios porque, até 2012, as commodities tinham cotações elevadas no mercado internacional, estimulando a economia e aumentando a arrecadação e, consequentemente, os gastos públicos ${ }^{26}$. Contudo, com a desaceleração da economia chinesa, os entes públicos brasileiros passaram a sofrer retração nas receitas. Além disso, as altas taxas de inflação e de juros contribuíram para o descontrole das finanças públicas. Diante desse cenário, foi apresentado o projeto do novo regime fiscal, divulgado como medida de austeridade que ajudaria o país a recuperar seu equilíbrio fiscal ${ }^{27}$. A ideia era aparentemente simples: a redução dos gastos geraria mais dinheiro para investir na recuperação econômica. Porém, não é isso que se verifica na realidade.

Ao não se considerar a variação do PIB para ajustar as verbas, com o crescimento econômico ao longo do tempo, a saúde vai progressivamente perdendo recursos. Isso porque o crescimento econômico aumenta a disponibilidade de recursos, que não podem ser aplicados nesse setor devido ao congelamento de gastos, enquanto que, no regime anterior, esses gastos seriam ajustados para se adequarem ao crescimento. Ironicamente, quanto melhor for o desenvolvimento econômico do país, maior será a perda para a saúde. A isso acrescenta-se o fato de que o ano-base para o congelamento, 2016, é historicamente um dos anos com menor arrecadação por conta da crise, de forma que, já de início, o teto dos gastos está aquém do esperado.

A título ilustrativo, tem-se a Tabela 1, elaborada na Nota Técnica n. 28 do Instituto de Pesquisa Econômica Aplicada (Ipea), que mostra a estimativa de perda de financiamento no setor da saúde ${ }^{28}$ - lembrando que, antes de ser aprovada, a EC n. 95/2016 foi tratada no Projeto de Emenda Constitucional n. 241 (PEC n. 241), na Câmara dos Deputados.

${ }^{26}$ SUZART, Janilson Antônio da Silva. Novo regime fiscal: uma análise sobre o impacto nos gastos sociais. In: XVII USP INTERNATIONAL CONFERENCE IN ACCOUNTING, 2017, São Paulo.

${ }^{27}$ Ib. Ibid.

${ }^{28}$ VIEIRA, Fabiola Sulpino; BENEVIDES, Rodrigo Pucci de Sá e. Os impactos do novo regime fiscal para o financiamento do Sistema Único de Saúde e para a efetivação do direito à saúde no Brasil, cit., p. 13. 
Tabela 1. Estimativa de impacto da PEC 241 para o financiamento federal do SUS - cenários para o período de 2017 à 2036

\begin{tabular}{|c|c|c|c|c|c|c|}
\hline \multirow{2}{*}{$\begin{array}{l}\text { Limite } \\
\text { inicial } 2016 \\
\text { conforme } \\
\text { PEC 241 }\end{array}$} & \multirow[b]{2}{*}{$\begin{array}{c}\text { Taxa de } \\
\text { crescimento } \\
\text { anual do PIB }\end{array}$} & \multirow{2}{*}{$\begin{array}{c}\text { Perda Acumulada } \\
\text { 2017-2036 em relação } \\
\text { à regra da EC } 86 \\
\text { (R\$ bilhões de 2016) }\end{array}$} & \multicolumn{4}{|c|}{ Valor do gasto federal com saúde } \\
\hline & & & $\begin{array}{l}\text { R\$ Bilhões } \\
\text { de } 2016\end{array}$ & $\begin{array}{c}\% \text { do } \\
\text { PIB }\end{array}$ & $\begin{array}{l}\% \text { da } \\
\text { RCL }\end{array}$ & $\begin{array}{c}\text { Valor per } \\
\text { capta em } \\
\text { R\$ de } 2016\end{array}$ \\
\hline \multirow[t]{4}{*}{$13,20 \%$} & $0,0 \%$ ao ano & -205 & 93,3 & 1,48 & 13,4 & 411 \\
\hline & $1,0 \%$ ao ano & -416 & 93,3 & 1,22 & 11,1 & 411 \\
\hline & $2,0 \%$ ao ano & -654 & 93,3 & 1,01 & 9,2 & 411 \\
\hline & LDO $2017\left(^{*}\right)$ & -999 & 94,2 & 0,84 & 7,6 & 415 \\
\hline \multirow[t]{5}{*}{$15,00 \%$} & $0,0 \%$ ao ano & 49 & 106 & 1,68 & 15,2 & 467 \\
\hline & $1,0 \%$ ao ano & -162 & 106 & 1,39 & 12,6 & 467 \\
\hline & $2,0 \%$ ao ano & -400 & 106 & 1,15 & 10,4 & 467 \\
\hline & LDO $2017(*)$ & -743 & 107 & 0,95 & 8,6 & 472 \\
\hline & \multicolumn{2}{|c|}{ * * Orçamento 2016} & 106,9 & 1,71 & 15,5 & 519 \\
\hline
\end{tabular}

Legenda: PIB - Produto Interno Bruto; RCL - Receita Corrente Líquida.

Fonte: do Instituto de Pesquisa Econômica Aplicada, 2016.

Consequentemente, destaca-se que o gasto em saúde per capita também cairá consideravelmente. Para 2016, a estimativa do gasto foi de R \$ 519,00 por habitante, ao passo que, em 2017, a previsão caiu para $\mathrm{R} \$ 446$, chegando a $\mathrm{R} \$ 411 \mathrm{em} \mathrm{2036}$, segundo estimativa do Ipea.

A redução dos recursos afetará principalmente a população mais vulnerável, que não tem acesso a planos privados e depende exclusivamente dos serviços prestados pelo SUS ${ }^{29}$. A dificuldade de acesso será maior nos estados mais pobres, que dependem em grande parte de transferências federais para financiar os serviços. Entre os serviços mais afetados, estarão os de prevenção e promoção da saúde, serviços basilares para as políticas de saúde pública ${ }^{30}$.

Os escassos recursos passarão a ser destinados à manutenção das estruturas já existentes, limitando por 20 anos a expansão do acesso à saúde nas regiões mais remotas e, consequentemente, aumentando as desigualdades sociais e regionais ${ }^{31}$. Dessa forma, a efetivação do direito à saúde será severamente prejudicada. Os princípios fundamentais do sistema, de integralidade e universalidade, não poderão se concretizar por causa da insuficiência de recursos. Planos de saúde privados populares não são grande ajuda, conforme pontua Sá ${ }^{32}$, pois a tendência de um sistema

\footnotetext{
${ }^{29}$ VIEIRA, Fabiola Sulpino; BENEVIDES, Rodrigo Pucci de Sá e. Os impactos do novo regime fiscal para o financiamento do Sistema Único de Saúde e para a efetivação do direito à saúde no Brasil, cit. ${ }^{30} \mathrm{lb}$. Ibid.

${ }^{31}$ Ib. Ibid.

${ }^{32}$ SÁ, Edvaldo Batista. O público e o privado no sistema de saúde: uma apreciação do projeto de plano de saúde acessível. Brasília-DF: Ipea, 2018. (Nota técnica n 47). Disponível em: http://www.ipea.gov.br/ portal/images/stories/PDFs/nota_tecnica/180201_nt_47_disoc.pdf.
} 
de planos populares é a concentração de tratamentos simples pelo seguro privado e de tratamentos complexos - de alta onerosidade -, pelo sistema público, além da transferência dos custos e riscos para o indivíduo, que já se encontra fragilizado nessa situação.

É importante ressaltar que, em tempos de crise econômica, a demanda por serviços de saúde tende a crescer. O número de desempregados no terceiro trimestre de 2017 atingiu a marca de 12,9 milhões, representando um aumento de $7,8 \%$ em relação ao mesmo período de $2016^{33}$. Com a perda dos empregos e consequente redução dos rendimentos familiares, há a perda da cobertura dos planos de saúde, tanto em relação aos planos individuais quanto aos planos coletivos ${ }^{34}$, os quais perfazem $66,5 \%$ do total, existindo uma forte associação entre renda e cobertura por plano privado de saúde ${ }^{35,36}$. Segundo o Sistema de Informações de Beneficiários, mantido pela Agência Nacional de Saúde Suplementar (ANS) e pelo Ministério da Saúde, havia 47.303.952 planos de saúde contratados no Brasil em setembro de 2017. Desse total, 31.483.875 eram planos empresariais ${ }^{37}$.

Dados do Sistema de Informações de Beneficiários da ANS revelam um crescimento negativo no número de beneficiários desde dezembro de 2015 totalizando $-2,5 \%$ em 2015; -3,3\% em 2016; e desacelerando em 2017, quando atingiu $-1,1 \%^{38}$. Com isso, mais famílias passaram a depender do sistema público, aumentando a demanda justamente em um período em que os recursos foram brutalmente reduzidos. O resultado tem sido uma falha no atendimento às necessidades básicas da população quando esta encontra-se em situação mais vulnerável.

Estudos internacionais comprovaram, ainda, uma piora considerável da saúde da população em tempos de austeridade, tanto física quanto mental, o que

\footnotetext{
${ }^{33}$ BRASIL tem 12,961 milhões de desempregados, diz IBGE. Época, 31 out. 2017. Disponível em: http:// epocanegocios.globo.com/Economia/noticia/2017/10/epoca-negocios-brasil-tem-desemprego-de-124no-trimestre-ate-setembro-diz-ibge.html. Acesso em: 19 nov. 2017.

${ }^{34}$ AGÊNCIA NACIONAL DE SAÚDE SUPLEMENTAR - ANS. Caderno de Informação da Saúde Suplementar beneficiários, operadoras e planos. Rio de Janeiro: ANS; set. 2016.

${ }^{35}$ BAHIA, Ligia et al. 0 mercado de planos e seguros de saúde no Brasil: uma abordagem exploratória sobre a estratificação das demandas segundo a PNAD 2003. Ciênc. saúde coletiva [online], v. 11, n. 4, p. 951-965, out./dez. 2006. http://dx.doi.org/10.1590/S1413-81232006000400017. Disponivel em: http://www. scielo.br/pdf/csc/v11n4/32332.pdf.

${ }^{36}$ ANDRADE, Mônica Viegas; MAIA, Ana Carolina. Demanda por planos de saúde no Brasil. In: SILVEIRA, Fernando Gaiger; SERVO, Luciana Mendes; MENEZES, Tatiane Menezes; PIOLA, Sérgio Francisco (Orgs.). Gasto e consumo das famílias brasileiras contemporâneas. Brasília-DF: Ipea, 2007. v. 2. Disponível em: http://www.ipea.gov.br/portal/images/stories/PDFs/livros/Livro_completo2.pdf.

${ }^{37}$ AGÊNCIA NACIONAL DE SAÚDE SUPLEMENTAR - ANS. Dados gerais. Beneficiários de planos privados de saúde, por cobertura assistencial (Brasil - 2009-2019). Disponível em: http://www.ans.gov.br/perfil-dosetor/dados-gerais. Acesso em: 15 abr. 2018.

${ }^{38} / \mathrm{d}$. Ibid.
} 
pressiona ainda mais os serviços de saúde ${ }^{39,40,41}$. A Grécia, país extremamente afetado pela crise europeia de 2008, é um bom exemplo: dados oficiais registram que os casos de suicídios aumentaram 17\% de 2007 a 2009, sendo que o Ministério da Saúde grego chegou a relatar um aumento de $40 \%$ entre 2010 e $2011^{42}$. Enquanto isso, o orçamento da saúde sofreu cortes de $5 \%$ de 2009 a 2011 e de $30 \%$ no primeiro trimestre de 2011. Essa combinação afetou especialmente as populações mais pobres, cuja procura por consultas e medicamentos aumentou rapidamente.

Outro ponto de atenção é a mudança no perfil demográfico do Brasil. Em 20 anos, estima-se que a população de idosos dobre de tamanho, enquanto a natalidade continuará em queda. Estimativas do Instituto Brasileiro de Geografia e Estatística (IBGE) apontam que a população acima de 60 anos passará de 12,1\% em 2016 para $21,5 \%$ em 2036 - um aumento de $96 \%$ - e a população com mais de 80 anos aumentará mais de 1,5 vez, indo de 3,5 milhões para 8,8 milhões de habitantes ${ }^{43}$. A Portaria n. 2.528/2006 ${ }^{44}$, que instituiu a Política Nacional de Saúde do Idoso, coloca que tal mudança etária acarreta maiores despesas com tratamentos médico-hospitalares, uma vez que o idoso consome em média mais serviços de saúde, com internações mais frequentes e tempo de ocupação maior do que outros grupos etários. Além disso, destaca-se que as doenças mais comuns em idosos têm caráter crônico e múltiplo, perdurando por vários anos e exigindo acompanhamento e intervenções contínuas ${ }^{45}$.

O que não se ressaltou à época dos debates sobre a aprovação do novo regime fiscal foi o potencial econômico da área da saúde. Comprovadamente, esse setor tem grande capacidade de gerar empregos e movimentar a economia. Por exemplo, o valor adicionado ao PIB nacional de 2013 pela área da saúde foi de 6,5\%, sendo o setor de saúde pública responsável por 2,3\%. O efeito multiplicador do gasto com saúde foi calculado em 1,7 , ou seja, para cada $\mathrm{R} \$ 1$ gasto com saúde no país, $\mathrm{R} \$ 1,70$ é acrescentado ao PIB, segundo dados de $2011^{46}$. Logo, a limitação dos gastos no

\footnotetext{
${ }^{39} \mathrm{SIMOU}$, E.; KOUTSOGEORGOU, E. Effects of the economic crisis on health and healthcare in Greece in the literature from 2009 to 2013: a systematic review. Health Policy, v. 115, n. 2-3, p. 111-119, 2014. http:// dx.doi.org/10.1016/j.healthpol.2014.02.002.

${ }^{40}$ VIEIRA, Fabiola Sulpino; BENEVIDES, Rodrigo Pucci de Sá. Crise econômica, austeridade fiscal e saúde: que lições podem ser aprendidas? Brasília-DF: Ipea, 2016. (Nota técnica $n^{\circ} 26$ ).

${ }^{41}$ STUCKLER, D.; BASU, S.; SUHRCKE, M.; COUTTS, A.; MCKEE, M. The public health effect of economic crises and alternative policy responses in Europe: an empirical analysis. Lancet, v. 374, p. 315-23, 2009.

${ }^{42}$ SIMOU, E.; KOUTSOGEORGOU, E. op. cit, p. 111-119.

${ }^{43}$ VIEIRA, Fabiola Sulpino; BENEVIDES, Rodrigo Pucci de Sá e. Os impactos do novo regime fiscal para o financiamento do Sistema Único de Saúde e para a efetivação do direito à saúde no Brasil, cit..

${ }^{44}$ MINISTÉRIO DA SAÚDE - MS. Portaria n. 2.528, de 19 de outubro de 1996. Aprova a Política Nacional de Saúde da Pessoa Idosa. Disponível em: http://bvsms.saude.gov.br/bvs/saudelegis/gm/2006/ prt2528_19_10_2006.html. Acesso em: 22 jan. 2019.

${ }^{45}$ BRITO, Maria da Conceição Coelho; FREITAS, Cibelly Aliny Siqueira Lima; MESQUITA, Karina Oliveira de; LIMA, Gleiciane Kélen. Envelhecimento populacional e os desafios para a saúde pública: análise da produção científica. Kairós Gerontologia, São Paulo, v. 16, n. 3, p. 161-178, 2013. Disponível em: https:// revistas.pucsp.br/kairos/article/download/18552/13738.

${ }^{46}$ ABRAHÃO, J.; MOSTAFA, J.; HERCULANO, P. Gastos com a política social: alavanca para o crescimento com distribuição de renda. Brasília-DF, 2011. (Comunicados do Ipea 75).
} 
setor não só prejudica apenas a população, como também gera um impacto negativo na própria economia que a medida visava a recuperar.

\subsection{0 impacto do novo regime fiscal na judicialização da saúde}

Por último, analisaremos o impacto do novo regime fiscal no fenômeno da judicialização da saúde. A CF/1988 previu ser a saúde um direito do indivíduo e um dever do Estado, devendo o acesso a ela ser universal e integral. Dessa forma, desde os anos 1990 tem-se assistido a um crescimento vertiginoso no número de ações no Judiciário exigindo determinados tratamentos ou remédios às expensas do Estado, fundamentando-os no artigo 196 da CF/1988.

O leading case reconhecido pela doutrina nacional sobre o tema é o Agravo Regimental no Recurso Extraordinário n. 271.286/RS (RE n. 271.286-8) ${ }^{47}$, em que o STF reconhece como dever do Estado distribuir gratuitamente medicamentos para tratamento da Aids a indivíduos desprovidos de recursos financeiros para arcar com seus custos. A decisão ressaltou o alcance do direito à saúde, qual seja, os serviços de saúde, a assistência farmacêutica e os serviços médico-hospitalares ${ }^{48}$. Por meio desse precedente, o STF admitiu a aplicabilidade direta e imediata das normas que positivam o direito à saúde, delimitando o que deve ser efetivado tanto na esfera individual quanto por meio de políticas públicas. Ao ver de $\mathrm{Gutier}^{49}$, é nesse momento que o Judiciário tomou para si a posição de protetor social e censor das omissões e negligências do Estado.

Adotando esse julgado como guia, o Judiciário foi gradativamente ampliando as hipóteses de fornecimento de tratamentos e medicamentos não previstos nas políticas públicas nem em planos de saúde privados, ampliando também meios de coerção do Estado para que cumpra as decisões judiciais (como bloqueio dos recursos públicos e multa diária). A partir do RE n. 407.902/RS ${ }^{50}$, de 26 de maio de 2009, o STF também reconheceu ao Ministério Público "legitimidade para ingressar em juízo com ação civil pública visando a compelir o Estado a fornecer medicamento indispensável à saúde da pessoa individualizada", dando ao direito à saúde caráter indisponível. Tal argumento foi expandido no Recurso Especial n. 668.216/SP ${ }^{51}$, em

\footnotetext{
${ }^{47}$ SUPREMO TRIBUNAL FEDERAL - STF. AGRG. no Recurso Extraordinário n. 271.286-8 do Rio Grande do Sul. Disponivel em: http://redir.stf.jus.br/paginadorpub/paginador.jsp?docTP=AC\&doclD=335538. Acesso em: 22 jan. 2019.

${ }^{48}$ GUTIER, Murillo Sapia; CORREIA JÚNIOR, Rubens; VENTURA, Carla A. Arena. 0 direito fundamental à saúde e a judicialização no Brasil: a saúde como direito humano e sua tutela processual. Revista Brasileira de Direito Processual: RBDPro, Belo Horizonte, v. 23, n. 89, p. 47-64, jan./mar. 2015.

${ }^{49} / \mathrm{lb}$. Ibid.

${ }^{50}$ SUPREMO TRIBUNAL FEDERAL - STF Recurso Extraordinário n. 407-902. Disponível em: http://portal.stf. jus.br/processos/detalhe.asp?incidente=2175787. Acesso em: 22 jan. 2019.

${ }^{51}$ SUPERIOR TRIBUNAL DE JUSTIÇA - STJ. Recurso Especial n. 668.216. Disponível em: https://ww2.stj.jus. $\mathrm{br} / \mathrm{processo} / \mathrm{revista} /$ documento/mediado/?componente=ITA\&sequencial=679581\&num_registro $=2004$ 00999090\&data=20070402\&formato=PDF. Acesso em: 22 jan. 2019.
} 
que o Superior Tribunal de Justiça (STJ) considerou abusiva cláusula de planos de saúde que restringia a cobertura a apenas alguns tipos de tratamento, uma vez que a cura não se alcançaria por procedimentos isolados.

Assim, a posição dos juízes tem sido bastante receptiva aos pedidos, causando considerável impacto para o orçamento da saúde. Nos últimos cinco anos, a quantidade de processos pleiteando tratamentos e medicamentos ainda não cobertos pelo SUS aumentou $92 \%{ }^{52}$. Uma auditoria realizada pelo Tribunal de Contas da União (TCU) revelou que, entre 2008 e 2015, os gastos do Ministério da Saúde para cumprir decisões judiciais aumentaram aproximadamente $1.300 \%$, saindo de R\$ 70 milhões em 2008 para cerca de R\$ 1 bilhão em 2015. Os estados de São Paulo, Minas Gerais e Santa Catarina gastaram juntos, em 2013 e 2014, mais do que a União no mesmo período. No total de despesas registradas nos três estados, os medicamentos representaram mais de $80 \%$, sendo que 19 medicamentos responderam por mais de $50 \%$ em São Paulo e Santa Catarina, entre eles nove fármacos não incorporados ao SUS ${ }^{53}$.

Como se pode observar, as decisões judiciais geram grande impacto no orçamento da saúde, uma vez que parte considerável dos recursos acaba sendo destinada para cumpri-las, em detrimento da realização das políticas públicas.

Um dos conceitos mais utilizados nesse meio é o das "escolhas trágicas": de um lado, a premissa de que os recursos da saúde são necessariamente limitados e, de outro, a ideia de que a demanda sempre tende ao crescimento. Newdick ${ }^{54}$ pontua que necessidades de saúde são praticamente infinitas, enquanto os recursos para atendê-las não o são; e a saúde, apesar de ser um bem fundamental e de especial importância, não é o único bem que uma sociedade tem interesse em usufruir. Tal contradição resulta em um problema de escassez que deve ser resolvido pela gestão por meio de escolhas de alocação, priorizando determinados serviços ${ }^{55}$. Tais escolhas, em teoria, são pensadas e estudadas como parte do plano de governo e visam a atender da melhor maneira possível os interesses sociais coletivos. Além disso, são atos de um representante eleito, um agente democraticamente legitimado para tomar decisões.

O debate começa quando os que foram preteridos nas escolhas orçamentárias passam a exigir por via judicial a tutela de seus direitos. O Poder Judiciário,

\footnotetext{
${ }^{52}$ PIERRO, Bruno de. Demandas crescentes. Pesquisa FAPESP, ed. 252, fev. 2017. Disponível em: http:// revistapesquisa.fapesp.br/2017/02/10/demandas-crescentes/. Acesso em: 17 nov. 2017.

${ }^{53}$ TRIBUNAL DE CONTAS DA UNIÃO - TCU. Relatório de Auditoria TC 009.253/2015-7. Relator: Bruno Dantas. Sessão: 16/08/2017. Disponível em: http://portal.tcu.gov.br/imprensa/noticias/aumentam-os-gastospublicos-com-judicializacao-da-saude.htm. Acesso em: 15 abr. 2018.

${ }^{54}$ NEWDICK, Christopher. Who should we treat? rights, rationing, and resources in the NHS. Oxford: Oxford University Press. 2005. http://dx.doi.org/10.1093/acprof:oso/9780199264186.001.0001. Published to Oxford Scholarship Online, Mar. 2012.

${ }^{55}$ FERRAZ, Octávio Luiz Motta; VIEIRA, Fabíola Supino. Direito à saúde, recursos escassos e equidade: os riscos da interpretação judicial dominante. Tribunal de Contas da União Dados, Rio de Janeiro, v. 52, n. 1, p. 223-251, jan./mar. 2009. http://dx.doi.org/10.1590/S0011-5258200900010000.
} 
nesses casos, atua fora de suas competências típicas, levando ao questionamento de sua legitimidade democrática, sua competência constitucional e sua formação técnica para proferir decisão que impacta diretamente políticas públicas ${ }^{56}$. Além de serem agentes de legitimidade duvidosa, uma vez que não foram eleitos por processos democráticos, em geral os magistrados não avaliam as questões de uma perspectiva macro, inclinando-se a privilegiar o direito individual em detrimento do planejamento estatal - enfim, as escolhas trágicas são feitas, mas com base no interesse individual.

Soma-se a essa iniquidade o fato de que o acesso ao Judiciário ainda é restrito a uma pequena parte da população, de modo a favorecer aqueles que podem receber esse serviço (no geral, parcelas com nível socieconômico mais elevado). Assim, os que já possuem condições de saúde comparativamente melhores, por sua posição social, são ainda beneficiados por seu acesso facilitado à Justiça, contribuindo para a transformação do SUS em perpetuador e contribuinte da desigualdade ${ }^{57}$.

A judicialização deve ser entendida como um fenômeno indicativo da falha do Estado em prover um determinado direito. A piora nas condições socioeconômicas da população gera aumento nas demandas por serviços públicos. Como já demonstrado, uma das consequências do novo regime fiscal é o aumento no número de usuários dos serviços públicos, tanto pelo desemprego e pelo aumento da expectativa de vida, quanto por uma queda geral no estado de saúde da população diante da conjuntura nacional de escassez, pressionando ainda mais o sistema. Ressalta-se que a judicialização é um meio gerador de desigualdade ${ }^{58}$, uma vez que os indivíduos atendidos com prioridade no sistema são aqueles que têm acesso ao Judiciário, em geral, pessoas de condição privilegiada. Assim, em um ambiente tendente ao aumento da pobreza e da desigualdade social, a judicialização é mais um elemento em desfavor das camadas em situação vulnerável.

Entramos, pois, em um círculo vicioso: com a redução dos recursos destinados à saúde, tem-se a queda na qualidade e no acesso ao atendimento, o que gera mais ações judiciárias cobrando o serviço, que, afinal, é um direito fundamental protegido pela $\mathrm{CF} / 1988$. No entanto, ao cumprir as liminares judiciais, os recursos disponíveis para a saúde são ainda mais esvaziados, contribuindo para a depauperação do sistema.

Dessa forma, o novo regime fiscal contribui diretamente para o agravamento de uma situação já crítica no país.

\footnotetext{
${ }^{56}$ WANG, Daniel Wei; VASCONCELLOS, Natália Pires de; OLIVEIRA, Vanessa Elias de; TERRAZAS, Vanessa Vargas. Os impactos da judicialização da saúde no município de São Paulo: gasto público e organização federativa. Revista de Administração Pública - RAP, Rio de Janeiro, v. 48, n. 5, p. 1191-1206, 2014.

${ }^{57}$ FERRAZ, Octávio Luiz Motta; VIEIRA, Fabíola Supino. op. cit., p. 223-251.

${ }^{58}$ Id., loc. cit.
} 


\section{Considerações finais}

Diante do acima exposto, percebe-se que o financiamento da saúde no Brasil sempre foi deficitário. O Estado demorou a assumir responsabilidades no âmbito da saúde pública, só o fazendo efetivamente após movimentos populares pressionarem pela constitucionalização da saúde e pela criação de um sistema único, universal e integral.

De 1990, ano da criação do SUS, até 2012, há um movimento de progressividade nos investimentos em políticas públicas, com verbas crescentes sendo destinadas ao setor. Contudo, a partir de 2015, usando a crise econômica como fundamentação, a saúde pública no país passa a sofrer ataques na forma de cortes em seu orçamento. As EC n. 86/2015 e n. 95/2016, de constitucionalidade já questionada perante o STF, representam a política de austeridade que toma conta do país, limitando os gastos em um setor essencial.

Com a piora nas condições de vida, a população tende a precisar cada vez mais do sistema público, justamente no momento em que este se encontra mais debilitado. Nesse cenário, a judicialização aparece como uma saída para aqueles que possuem acesso ao Judiciário. As decisões dos magistrados acabam por burlar o sistema, dando preferência no atendimento e dificultando ainda mais o acesso das camadas mais baixas da população, as mais atingidas e dependentes de tais serviços.

Dessa forma, uma medida (a EC n. 95/2016) anunciada como parte da salvação econômica do país, aprovada a fim de acelerar a recuperação da crise que ele atravessa, na verdade tem um impacto negativo muito maior do que seus potenciais benefícios. O novo regime fiscal não apenas representa uma medida de austeridade nunca antes colocada em prática por qualquer país no mundo, como também representa uma significativa redução no financiamento dos direitos sociais. Um congelamento de 20 anos nos gastos primários do Estado significa um atraso de 20 anos nas políticas públicas de saúde. Ao aplicar esse regime, o Brasil está retrocedendo na história e colocando em risco todo o esforço de criação de um sistema de saúde que fosse gratuito e integral para todos. Caso o novo regime continue sendo aplicado, talvez o sistema de financiamento da saúde seja ainda mais precário em 2036 do que ao tempo de sua criação.

\section{Referências}

ABRAHÃO, J.; MOSTAFA, J.; HERCULANO, P. Gastos com a política social: alavanca para o crescimento com distribuição de renda. Brasília-DF, 2011. (Comunicados do Ipea 75).

AGÊNCIA NACIONAL DE SAÚDE SUPLEMENTAR - ANS. Dados gerais. Beneficiários de planos privados de saúde, por cobertura assistencial (Brasil - 2009-2019). Disponível em: http://www.ans.gov.br/perfil-do-setor/dados-gerais. Acesso em: 15 abr. 2018. 
AGÊNCIA NACIONAL DE SAÚDE SUPLEMENTAR - ANS. Caderno de Informação da Saúde Suplementar beneficiários, operadoras e planos. Rio de Janeiro: ANS; set. 2016.

ANDRADE, Mônica Viegas; MAIA, Ana Carolina. Demanda por planos de saúde no Brasil. In: SILVEIRA, Fernando Gaiger; SERVO, Luciana Mendes; MENEZES, Tatiane Menezes; PIOLA, Sérgio Francisco (Orgs.). Gasto e consumo das famílias brasileiras contemporâneas. Brasília-DF: Ipea, 2007. v. 2. Disponível em: http://www.ipea.gov.br/portal/images/stories/ PDFs/livros/Livro_completo2.pdf.

BAHIA, Ligia et al. O mercado de planos e seguros de saúde no Brasil: uma abordagem exploratória sobre a estratificação das demandas segundo a PNAD 2003. Ciênc. saúde coletiva [online], v. 11, n. 4, p. 951-965, out./dez. 2006. http://dx.doi.org/10.1590/S141381232006000400017. Disponível em: http://www.scielo.br/pdf/csc/v11n4/32332.pdf.

BRASIL tem 12,961 milhões de desempregados, diz IBGE. Época, 31 out. 2017. Disponível em: http://epocanegocios.globo.com/Economia/noticia/2017/10/epoca-negocios-brasiltem-desemprego-de-124-no-trimestre-ate-setembro-diz-ibge.html. Acesso em: 19 nov. 2017.

BRITO, Adriano; COSTAS, Ruth. Brasil rebaixado: com perda de grau de investimento, dólar e juros podem ficar mais caros. BBC, 09 set. 2015. Disponível em: http://www.bbc.com/ portuguese/noticias/2015/09/150909_brasil_rebaixamento_ab.

BRITO, Maria da Conceição Coelho; FREITAS, Cibelly Aliny Siqueira Lima; MESQUITA, Karina Oliveira de; LIMA, Gleiciane Kélen. Envelhecimento populacional e os desafios para a saúde pública: análise da produção científica. Kairós Gerontologia, São Paulo, v. 16, n. 3, p. 161-178, 2013. Disponível em: https://revistas.pucsp.br/kairos/article/download/18552/13738.

CONSELHO NACIONAL DE SECRETÁRIOS DE SAÚDE - CONASS. O financiamento da saúde. Brasília-DF: Conass, 2011 (Coleção Progestores - para entender a gestão do SUS, n. 2).

FERRAZ, Octávio Luiz Motta; VIEIRA, Fabíola Supino. Direito à saúde, recursos escassos e equidade: os riscos da interpretação judicial dominante. Dados, Rio de Janeiro, v. 52, n. 1, p. 223-251, jan./mar. 2009. http://dx.doi.org/10.1590/S0011-5258200900010000.

FUNCIA, Francisco. Nota de esclarecimento a respeito do cálculo das perdas decorrentes do início da vigência da nova regra da Emenda Constitucional no 86/2015 para calcular a aplicação mínima da União em ações e serviços públicos de saúde. Domingueira, Campinas, n. 4, 12 abr. 2015. Disponível em: http://www.idisa.org.br/img/File/Domingueira\%20da\%20 Sa\%C3\%BAde\%20-\%20004\%202015\%20-\%2012\%2004\%202015.pdf. Acesso em: maio 2015.

GUTIER, Murillo Sapia; CORREIA JÚNIOR, Rubens; VENTURA, Carla A. Arena. O direito fundamental à saúde e a judicialização no Brasil: a saúde como direito humano e sua tutela processual. Revista Brasileira de Direito Processual: RBDPro, Belo Horizonte, v. 23, n. 89, p. 47-64, jan./mar. 2015.

MINISTÉRIO DA SAÚDE. ORGANIZAÇÃO PAN-AMERICANA DA SAÚDE. Financiamento público de saúde. Brasília-DF: Ministério da Saúde, 2013. (Série ECos - Economia da Saúde para a Gestão do SUS; Eixo 1, v. 1). 
NEWDICK, Christopher. Who should we treat? rights, rationing, and resources in the NHS. Oxford: Oxford University Press. 2005. http://dx.doi.org/10.1093/acprof:o so/9780199264186.001.0001. Published to Oxford Scholarship Online, Mar. 2012.

OLIVEIRA, Fabrício. Economia e política das finanças públicas no Brasil. São Paulo: Hucitec, 2012.

PAIVA, Carlos Henrique Assunção; TEIXEIRA, Luiz Antônio. Reforma sanitária e a criação do Sistema Único de Saúde: Notas sobre contextos e autores. Hist. cienc. saude-Manguinhos [online]. Rio de Janeiro, v. 21, n. 1, p. 15-35, jan./mar. 2014. http://dx.doi.org/10.1590/ S0104-59702014000100002. Disponível em: http://www.scielo.br/pdf/hcsm/v21n1/01045970-hcsm-21-1-00015.pdf.

PIERRO, Bruno de. Demandas crescentes. Pesquisa FAPESP, ed. 252, fev. 2017. Disponível em: http://revistapesquisa.fapesp.br/2017/02/10/demandas-crescentes/. Acesso em: 17 nov. 2017.

PINTO, Élida Graziane. Novo regime fiscal e a constitucionalização do contingenciamento das despesas primárias obrigatórias. Physis, Rio de Janeiro, v. 26, n. 4, p. 1097-1101, out. 2016. http://dx.doi.org/10.1590/s0103-73312016000400002. Disponível em: http://www.scielo.br/ scielo.php?script=sci_arttext\&pid=S0103-73312016000401097\&lng=en\&nrm=iso.

PIOLA, Sérgio F.; PAIVA, Andrea Barreto de; SÁ, Edvaldo Batista de; SERVO, Luciana Mendes Santos. Financiamento público da saúde: uma história à procura de rumo. BrasíliaDF: Ipea, 2013. (Texto para Discussão ${ }^{\circ}$ 1846). Disponível em: http://repositorio.ipea.gov. br/bitstream/11058/1580/1/TD_1846.pdf.

SÁ, Edvaldo Batista. O público e o privado no sistema de saúde: uma apreciação do projeto de plano de saúde acessível. Brasília-DF: Ipea, 2018. (Nota técnica no 47). Disponível em: http://www.ipea.gov.br/portal/images/stories/PDFs/nota_tecnica/180201_nt_47_disoc.pdf.

SALVADOR, Evilasio. A privatização da previdência do servidor público: a Funpresp e a financeirização das aposentadorias e pensões. Cadernos Aslegis, v. 43, p. 107-128, 2011. Disponível em: http://aslegis.org.br/files/cadernos/2011/Caderno43/CAD.43p107_A. privatizacao.da.previdencia.do.servidor.publico.a.fuvnpresp.e.a.financeirizacao.das. aposentadorias.e.pensoes.pdf.

SARLET, Ingo Wolfgang; FIGUEIREDO, Mariana Filchtiner. Algumas considerações sobre o direito fundamental à proteção e promoção da saúde aos 20 anos da Constituição Federal de 1988. Revista de Direito do Consumidor, São Paulo, v. 17, n.67, p. 125-172, jul./set. 2008.

SCAFF, Fernando Facury. Surge o orçamento impositivo à brasileira pela Emenda Constitucional 86. Conjur, 24 mar. 2015, https://www.conjur.com.br/2015-mar-24/contasvista-surge-orcamento-impositivo-brasileira-ec-86. Acesso em: 12 abr. 2018.

SIMOU, E.; KOUTSOGEORGOU, E. Effects of the economic crisis on health and healthcare in Greece in the literature from 2009 to 2013: a systematic review. Health Policy, v. 115, n. 2-3, p. 111-119, 2014. http://dx.doi.org/10.1016/j.healthpol.2014.02.002. 
STUCKLER, D.; BASU, S.; SUHRCKE, M.; COUTTS, A.; MCKEE, M. The public health effect of economic crises and alternative policy responses in Europe: an empirical analysis. Lancet, v. 374, p. 315-23, 2009.

SUZART, Janilson Antônio da Silva. Novo regime fiscal: uma análise sobre o impacto nos gastos sociais. In: XVII USP INTERNATIONAL CONFERENCE IN ACCOUNTING, 2017, São Paulo.

VIEIRA, Fabiola Sulpino; BENEVIDES, Rodrigo Pucci de Sá e. Os impactos do novo regime fiscal para o financiamento do Sistema Único de Saúde e para a efetivação do direito à saúde no Brasil. Brasília-DF: Ipea, 2016. (Nota técnica no 28).

VIEIRA, Fabiola Sulpino; BENEVIDES, Rodrigo Pucci de Sá e. Crise econômica, austeridade fiscal e saúde: que lições podem ser aprendidas? Brasília-DF: Ipea, 2016. (Nota técnica no 26).

WANG, Daniel Wei; VASCONCELLOS, Natália Pires de; OLIVEIRA, Vanessa Elias de; TERRAZAS, Vanessa Vargas. Os impactos da judicialização da saúde no município de São Paulo: gasto público e organização federativa. Revista de Administração Pública - RAP, Rio de Janeiro, v. 48, n. 5, p. 1191-1206, 2014.

Ana Luisa Pereira Agudo Romão - Graduanda em Direito pela Faculdade de Direito da Universidade de São Paulo (FDUSP). Voluntária no Centro de Estudos e Pesquisas em Direito Sanitário (Cepedisa).São Paulo/SP, Brasil.E-mail: ana.romao@usp.br 